تحفيز تكوين الكالس وظهور النموات الخضرية في نبات الهوهوبا in vitro خارج الجسم الحيات Simmondsia chinesis (Link) Schn.

\title{
In vitro Callus induction and Shoot proliferation in Jojoba Simmondsia chinesis (Link) Schn.
}

د. كاظم محمد ابراهيم

$$
\begin{aligned}
& \text { أشواق شنان عبد أشرو } \\
& \text { اروى عبد الكريم توفيق*" * }
\end{aligned}
$$

د ـ نبيل خلف العاني

قسم التقانة الاحيائيةـ كلية العلوم/ جامعة النهرين

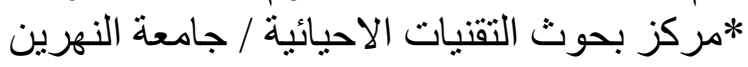
ت تلية العلوم للبنات

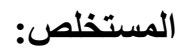

تعتبر شجرة الهوويا من النباتات المهمة على الصعيد الاقتصادي لاحتواء بذورها على نسبة عالية من الزيت الثمعي ، إذ يمتلك هذا الزيت صفات كيميائية وطييعية مهمة أدخلته في العديد من الاستعمالات الصناعية والتجارية وبعض الاستعمالات الطبية ، لذا تم وضع النبات قيد الدراسة المختبرية وتنفيذ تجربة عملية تداخلت فيها الاوكسينات والسايتوكاينينات والجبرلينات لمعرفة أفضل توليفة منهم في تأثير ها على استجابة البراعم المزروعة للتكشف والنمو الخضري واستحثاث الكالس على الأجزاء النباتية المتكونة ـ وقد تم استخدام بتركيز(2 أو5 ) ملغم/لتر ، Kin بتركيز (2.15 أو 5) ملغم/لتر، NAA بتركيز (0.018 ، 1 1، 2 أو 5) ملغم/لتر وأخيرا GA3 بتركيز(0.1 أو 0.2) ملفم/لتر ـ وقد أظهرت النتائج إن أعلى نسبة مئوية لاستحثاث الكالس على

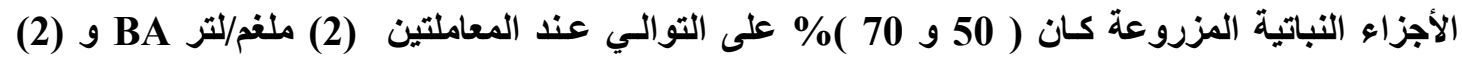

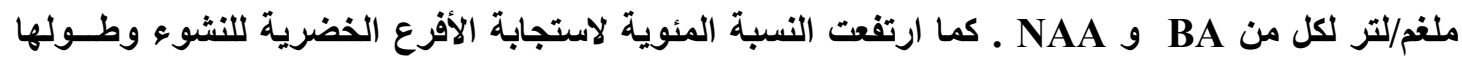
المتكونة عند المعاملتين المتضمنتين إضافة كل من Kin و NAA مع GA3 بتركيزيه (0.1 أو 0.2) ملغم/لتر بنسة (40 و44 )\% على التوالي ، على الرغم من ان طول الافرع الخضرية كان (2 و2.5 ) سم مما

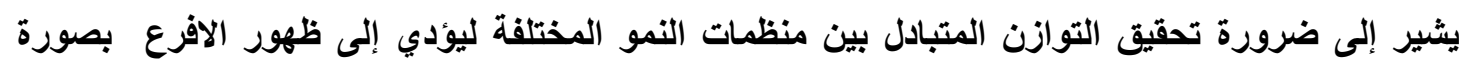

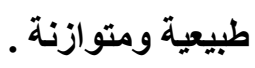

Abstract

From economic site; jojoba Simmondsia chinesis (Link) Schn. is very important shrub as its seeds contain high percent of oily wax. This wax composes natural and chemical charachteristics which makes shrub to be involved in many trade, manufacture and medical uses. In this study several interactions between auxins and cytokinins and gibbrellin were implemented to find out the best concentration for callus induction, vegetative growth and differentiation for experiments. BA at(2 or 5) $\mathrm{mg} / \mathrm{l}, \mathrm{NAA}$ at $(0.018,2,2,5) \mathrm{mg} / \mathrm{l}$ and $\mathrm{GA}_{3}$ at $(0.1$ or 0.2) $\mathrm{mg} / \mathrm{l}$ were used.Results showed that highest percent for callus induction were 
(50 and 70) \% respectively in the treatment (2) $\mathrm{mg} / \mathrm{l} \mathrm{BA}$ and (2) $\mathrm{mg} / \mathrm{l}$ for both $\mathrm{BA}$ and NAA. The results revealed that using Kin. plus NAA with $(0.1$ or 0.2$) \mathrm{mg} / \mathrm{l}$ GA $_{3}$, was the best concentration lead to high percent of differentiation for vegetative shoot were (40 and 44$) \%$ respectively. However, the length of vegetative shoots were $(2$ and 2.5$) \mathrm{cm}$ respectively, this indicates the importance of the balance between these phytohormones required for shoot growth.

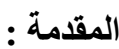

Caryophin و Menthol ، فضلا عن الفروقات الكيمياحيوية التي تم ملاحظتها بين بروتوبلاست خلايا الأوراق وخلايا الكالس إذ تميزت الأولى بغز ارة الكلوروبلاست اما الثانية فتميزت بتضاعف حجم البرتوبلاست ، في حين تماتلت نسب البروتين والدهون الكلية في كلا الخليتين (الأوراق والكالس) [5] ـ وتتمتع هذه النبتة بمواصفات مهمة كإحتياجها القليل إلى الماء وقدرتها العالية على تحمل العطش و الملوحة لارجة تجعلها مناسبة لجو الصحراء ، كما تمتاز بقلة حاجتها للرعاية من ناحية التسميد والتقليم والخدمة وقلة إصابتها بالأمر اض وعدم حاجتها للرش الوقائي ، ويتم إكثار هذا النبات بعدة

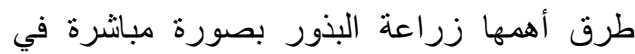
التربة على عمق من (2-5) سم ، إلا أن النباتات الناتجة قد تكون متغايرة ور اثبا ، أما الطريقة الثانية فهي الإكثار الخضري ( العقل ) إذ نتيح الطريقة الأخبرة التحكم في نسبة النباتات المؤنثة إلى لـى لإن المذكرة ، ويفضل أن تتر اوح نسبة النباتات المؤنثة عند الزراعة ما بين (90-95)\% ، بينما تكون نسبة (5-10)\% المنتقية نباتات مذكرة لتنتج ما ما

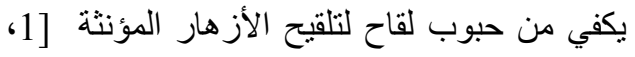
. [6، 3

وترجع أهمية هذا النبات لمحتواه الجيد من البروتينات ، الكلايكوسايدات ، الاسترات ، الاحماض ، و الكحولات الدهنية ، و الاهم من هذا كله هو احتواء بذوره على نسبة عالية من الزيت
يطلق على نبات الهو هوبا عدة أسماء منها الهو هوبا (Hohoba) ، الجوجوبا (Jojoba) ، جوز الماعز ، (Goat nut) أما اسمه العلمي فهو Simmondsia chinesis (Link) Schneider ( ) و الثجيرة من النباتات (Simmondsiaceae) المعرة تصل فترة حياتها (100- 200) عام ، موطنها الأصلي جنوب غرب أريزونا وكاليفورنيا وشمال المكسيك أي في المنطقة المشتركة بين الولايات المتحدة الأمريكية والمكسيك [1،2] . النبات شجيرة متفرعة يصل ارتفاعها ما بين (1-

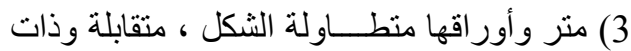

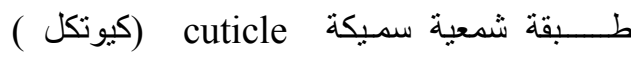

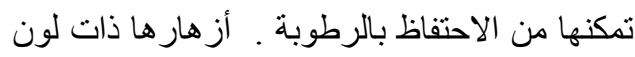
اصفر مخضر وتنشأ في إبط الأوراق وتكون فاقدة للبتلات ويتلقح النبات عن طريق الرياح لان النبات ثنائي المسكن (dioecious) ـ أما فترة التزهير فتستمر من آذار وحتى حزير ان ـ تبدأ الثجيرة عادة بإنتاج البذور بعد السنة الثانية أو الثالثة من زراعنها وعادة ما تكون هذه البذور متغايرة في الحجم وتصنف عادة إلى صغيرة ومتوسطة وكبيرة الحجم

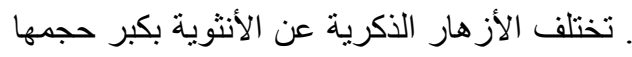
وترتيبها بهيئة عناقيد زهرية ، أما الأنثوية فتكون صغيرة وتحمل بصورة منفردة عند العقد الورقية [4،3] ويختلف الجنسين في محتواهما البروتيني ، Geranoil وبعض المركبات الثانوية مثل 
أيضا في برامج الحمية (لتقليل الوزن) لاحتوائه على مركب (Simmondsin) كما يستخدم في الطهي وفي صناعة حبر الطباعة والورنيش لمانس ويستخدم الثمع أو (الزيت المهدرج منه) في تلميع الأرضيات والأثاث و السيار ات وللتغليف الوات التي لمحاصيل الفاكهة والخضر ، وفي صناعة النسيج

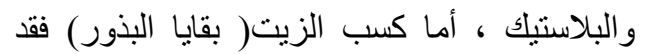

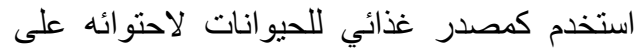
\%) بروتين فضلا عن الكاربو هيدرات والألياف ، وكسماد للأراضي الزراعية لاحتو ائه

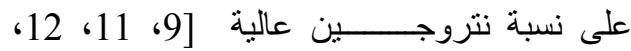
13، 14، 15، 16 ] . . و لأهمية النبات فقد حاول العلماء توظيف تقنية زراعة الأنسجة النباتية في

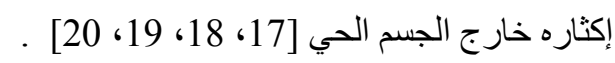

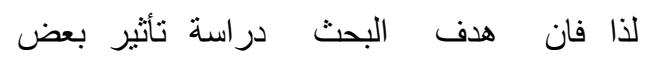

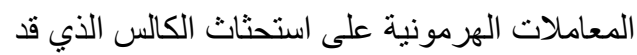
يكون مصدر لنشوء الزروعات فضلا عن كونه

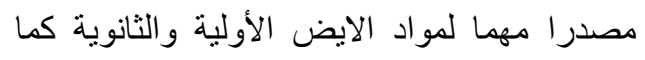
هدفت الدراسة أيضا إلى معرفة تأثثير هذه المعاملات الهرمونية في تحفيز ظهور النموات

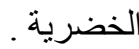

(تركيز 5.25\%) وبنسبة تخفيف (1:1) مع ماء مقطر معقم ، ثم أضيفت قطرات من المادة الناشرة

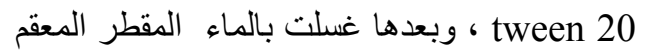
ثلاث مرات [23] لازالة تأثثير المادة المعقمة . قطعت إلى طول (1) سم وزرعت في قناني زجاجية (vials) ذات أبــعاد ( 25x150) ملم .

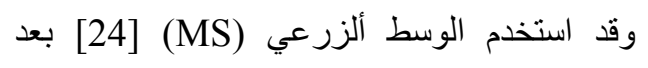
إضافة السكروز بمقدار (30)غم/لتر وتعديل اسه السه الهيدروجيني إلى (5.7) .أضيف الاكار بمقدار (6) غم/لتر بعد تعقيمه في جهاز الموصدة الكهربائي على درجة حرارة(121)م وضغط 1.04 كم/م3
(50\%) من وزنها [7، 8، 9] ويتكون هذا الزيت من (97\%) شمع و (3\%) احماض دهنية وكحولية حرة فضلا عن احتوائه على مو اد مانعة للتأكسد . يتميز هذا الزيت بان جزيئاته تتكون من سلسلة

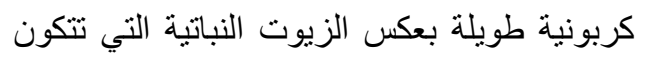
من الاحماض الدهنية والكلسرين ، الامر الذي لري يجعل زيت الهو هوبا ليس دهنا بل هو شمع سائل

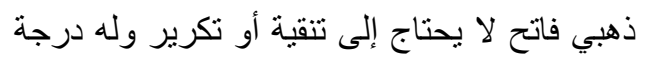
حفظ جيدة لوجود مواد طبيعية مضادة للأكسدة ، وله معدل لزوجة عالي ونقطة وميض و اشتعال ودرجة ثبات عالية ـ قليل التطاير ويتحمل درجات الحرارة المرتفعة ، كما يعد زيته من الدهون قليلة الطــــاقة (Low energy fat) [9، 10] ولهذه الصفات الطبيعية والكيميائية فقد استعمل هذا الزيت السائل في الآلات التي تعمل في درجات حرارة وضغوط عالية وفي الآلات ذات الحركة الاقيقة لتخفيف الاحتكاك بين التروس والمحاور ، كما استخدم في صناعة مواد التجميل كزيوت الثعر و الثامبوات و الصابون وكريمات الوجه ومرطبات البشرة ، فضلا عن استخداماته الصبدلانية كمثبط لنمو بعض أنواع البكتريا والفيروسات (مضاد للالتهابات (Anti-inflammatory) ويستخدم المواد وطر ائق العمل : الد تم الحصول على الأجزاء النباتية من الثجيرات

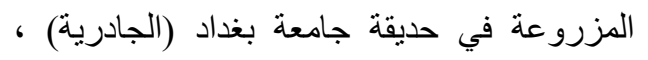
استخدمت العقل الساقية الحاوية على البراعم كمزدرع (21) (Explants) لنبات الهوهوبا

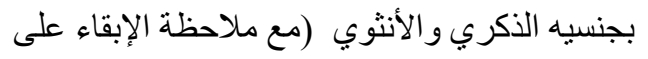
جزء بسيط من سويق الورقة بعد إزالة الأوراق

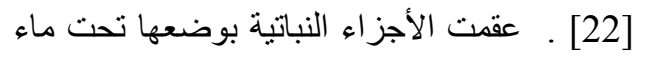
حنفية جاري لمدة لا تقل عن ساعة واحدة ثم نقلت

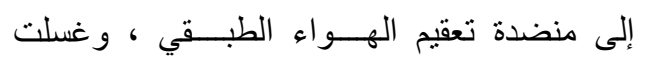
بالكحول الاثيلي 70\% لمدة دقيقة واحدة ، ثم عقمت ك ونم سطحيا بمحلول هاييوكلورات الصوديوم التجاري 
إضاءة (16) ساعة/يوم ولمدة شهرين تم بعدها

تدوين الملاحظات الخاصة بمؤشر ات النمو ـ

2 - مرحلة التجذير:

اختبرت منظمات النمو BA بتركيز(0.5 أو1)

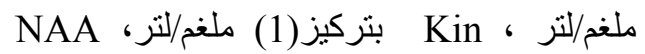
بتركيز (1 أو 2) ملغم/لتر ، IAA بتركيز (1) ملغم/لتر و BA بتركيز(1و5) ملغم/لنز بصور هم المفردة والمتداخلة بعد إضافتها إلى الوسط الزرعي لمردي ، MS ) باختلاف قواه الملــــية (MS) ( 1/5MS , 1/3MS ، 1/4MS ، 1/2MS لاراسة قابلية الزروعات على التجذير ، وقد أهملت النتائج بعد شهرين من زراعتها لعدم لعدم استجابة الزرو عات في تكوين المجموع الجذري .

السابع من زراعة الاجزاء النباتية على الوسط

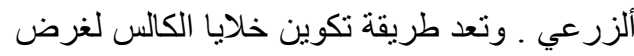

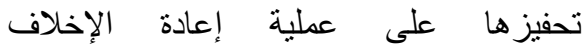
Regeneration عمليات الإكثار خارج الجسم الحي ، وقد تمكن الباحثون [18] من النجاح في إكثار نبات الهو هوبا خارج الجسم الحي بعد استحثاث خلايا الكالس وتحفيز ها على الإخلاف لتكوين نبيتات جديدة .
لمدة (15) دقيقة ، وقد أضيفت منظمات النمو إلى الوسط المذكور لدر اسة مرحلتين من نطور النبات هما: 1- مرحلة النشوء (مرحلة تكوين الأجزاء

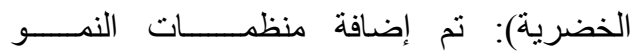
Kin بتركيز(2 أو 5) ملغم/لتر و B

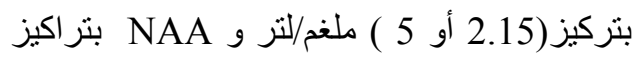

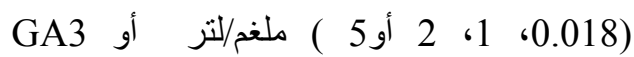
بتركيز(0.1 أو 0.2 ) ملغم/لتر إلى الوسط ألزرعي

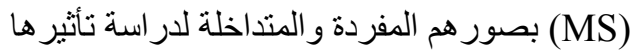
في تحفيز البراعم الابطية على النمو ـ استخدم (15) مكرر الكل من النباتات الذكرية والأنثوية أي لهي بواقع (30) مكرر لكل معاملة . هضنت الزروعات على درجة حرارة (28 - 25) وفترة النتائج والمناقشة يوضح الشكل (1) النسبة المئوية لنشوء وتكوين خلايا الكـالس ، فقد أعطت المــعاملة المتكونة من تركيز (2) ملغم /لتزر لكل من BA و NAA أعلى نسبة في نشوء الكالس والبالغة (70)\% ، تليها

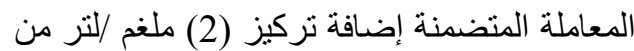
BA

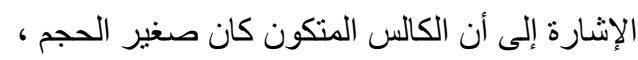
صلبا ، ابيض اللون وكان نشوءه بعد الأسبوع 


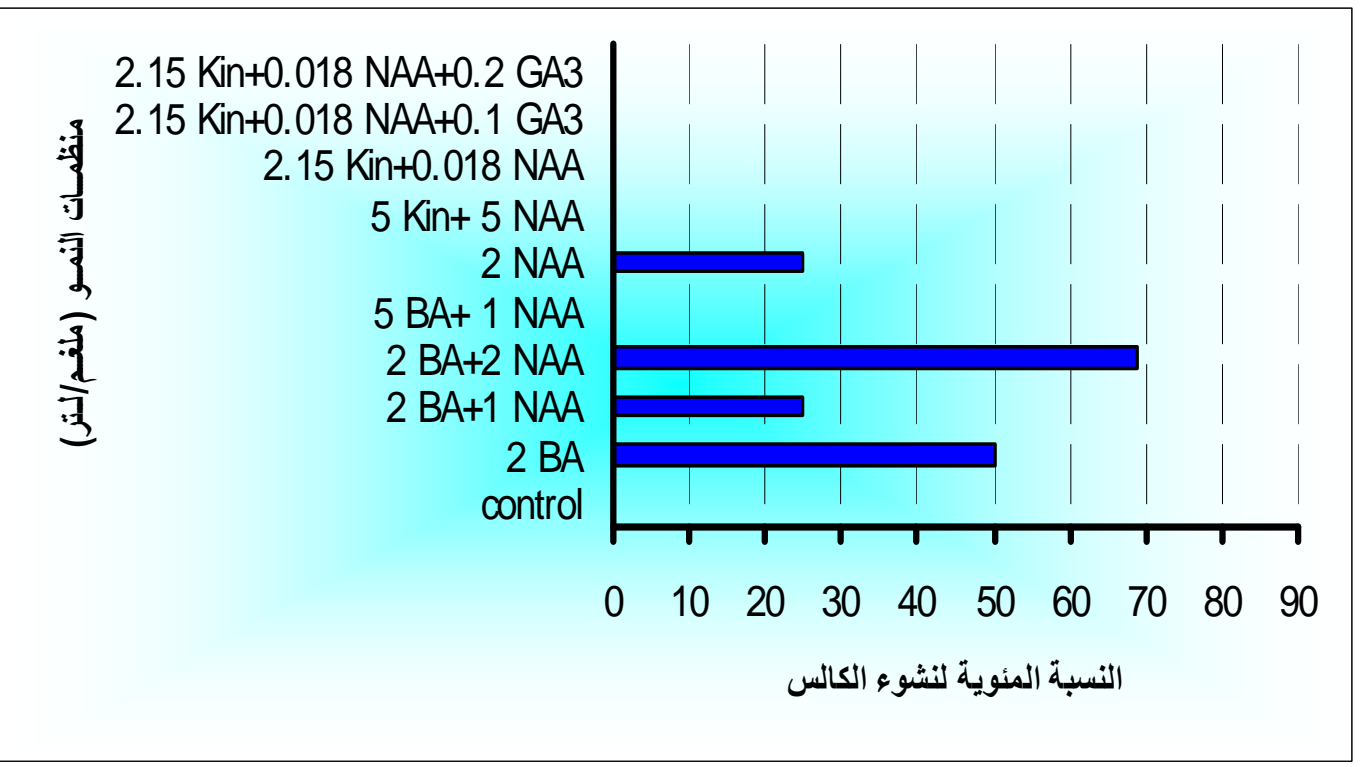

شكل(1) تأثير تراكيز منظمات النمو المستخدمة في النسبة المئوية لاستحثاث الكالس لنبات الهوهوبا بعد شهرين من

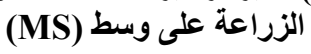

المتمثلتين بإضافة GA3 بتركيز(0.1 و0.2 )0

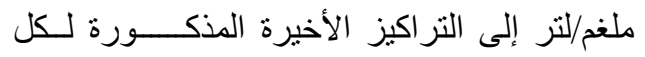

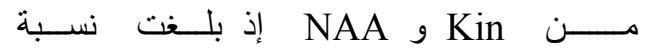
الاستجابــة للنشـــوء (44 و40) \% و على التوالي

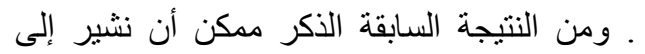
نجاح معظم توليفات منظمات النمو في رفع نسبة الاستجابة لنشوء الأفرع الخضرية مقارنة مع معاملة السيطرة و التي لا تزيد فيها نسبة الاستجابة

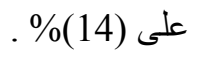

كما يبين الثكل (2) تباين تأثير منظمات النمو النباتية في النسبة المئوية لنشوء الأفرع الخضرية

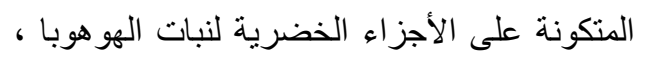
إذ حصل تأثير ايجابي واضح عند إضافة BA أنداء بتركيز(2) ملغم /لتزر، وكذللك عند إضافة كل من

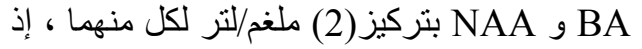
بلغت نسبة الاستجابة (71 و 44) \% ع على التو الي ، كما أدت إضافة منظمي النمو Kin بتركيز(2.15) ملغم/لتز وNAA بتركيز (0.018) ملغم/لتر إلى إعطاء نسبة استجابة (58)\% تلتها المعاملتين 


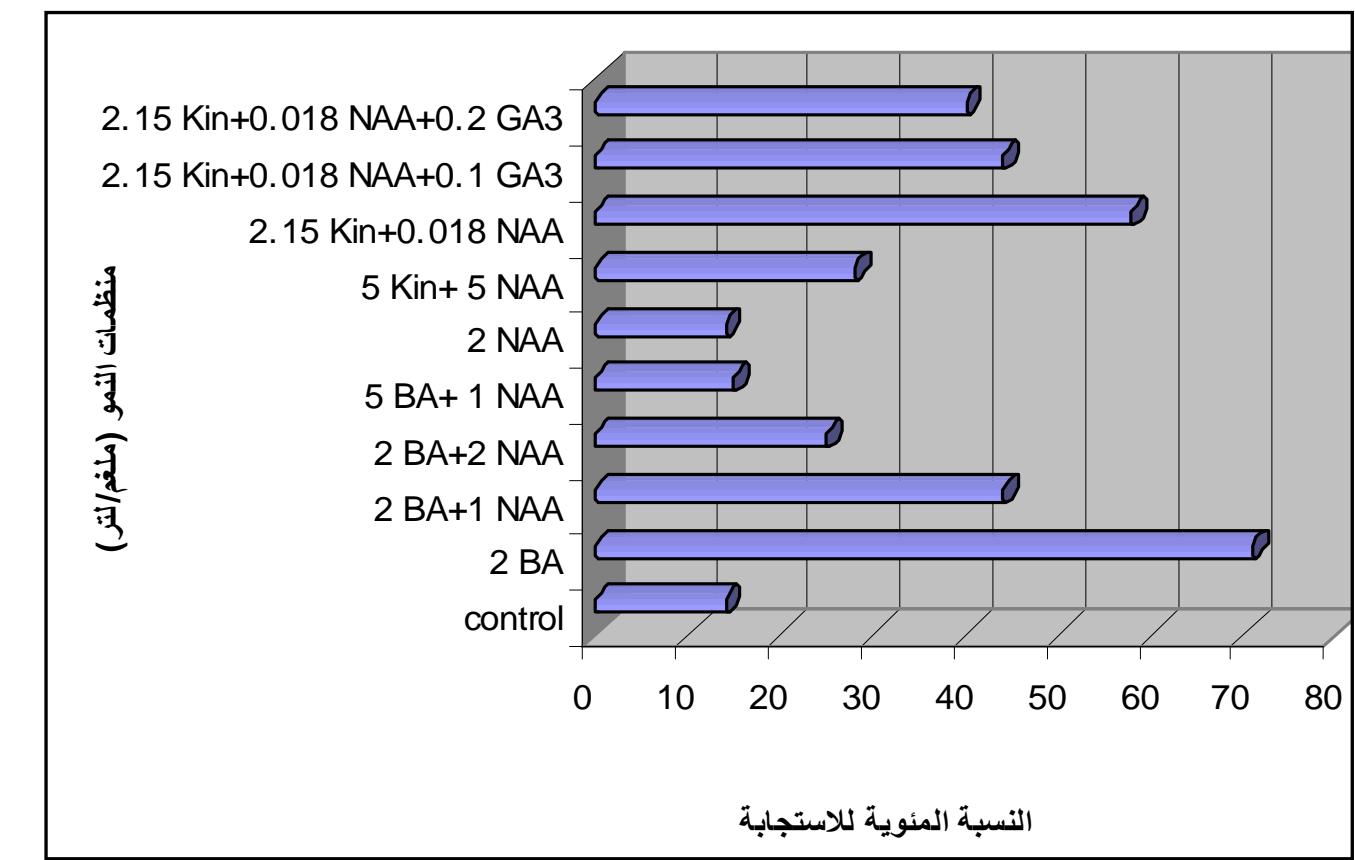

شكل(2) تأثير تراكيز منظمات النمو المستخدمة في النسبة المئوية لاستجابة ونشوء الأفرع الخضرية لنبات الهوهوبا

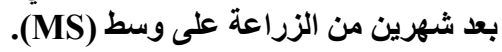

وكبر حجمها كذللك الجبرلينـات التي تعدل على

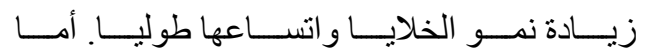

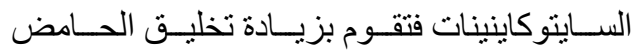

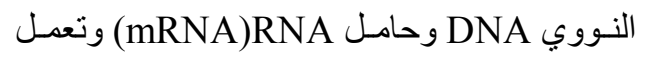

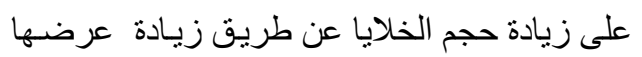

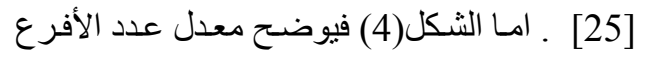
الخضرية المتكونة ، ويتبين منه ان المعدل (2) كان

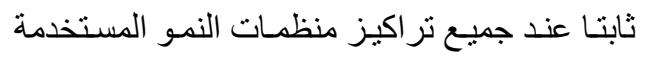
قبد الدراسة ، إذ تم نشوء الأفرع من العقد الابطية

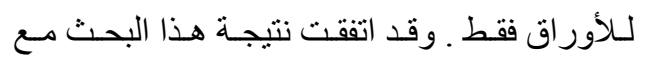

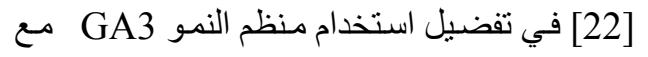
الاوكسينات و السايتو كاينينات ضمن معاملات إكثار نبات الهو هوبا باستخدام تقنية الإكثار خـارج الجسم الحي ـلوجوب تحقيق التوازن المتبـادل بـين هذه

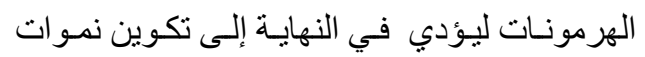

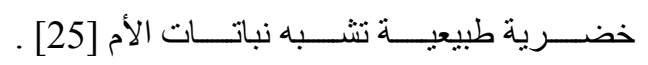

أمــا الثــكل (3) فيوضــــ تـأثير منظمــات النـــو

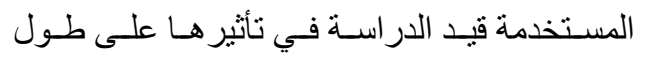

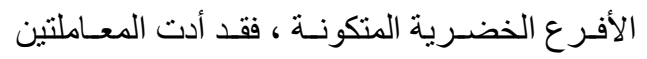
المتضـنتين إضـافة GA3 مـع كل مـن Kin و

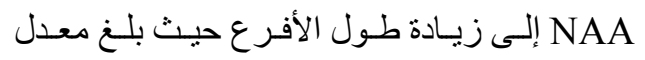

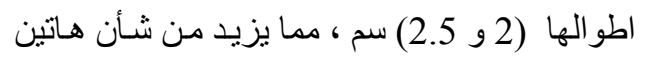
المعـاملتين لارتفاع كل من نسبة الاستجابة لنشوء

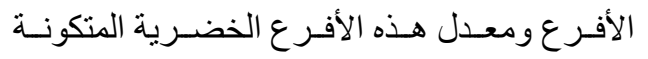
مقارنة مع سائر المعاملات شكل( 4) و التي لوحظ

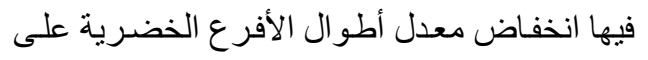

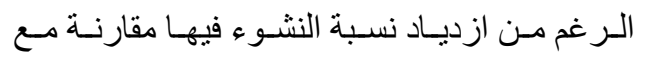
معاملة السيطرة و التي لا تزيد فيها نسبة الاستجابة عن (14)\% ـ ويعود ذلك للدور الكبير الذي تلعبه

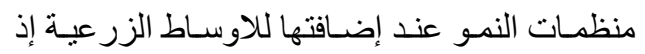
تعمل الاوكسينات على إمداد الخلايـا بالماء وكذللك المســاعدة على تنشـيط إنتـاج الاحمــاض الامينيـة خاصة RNA مساعدة بذلك على استطالة الخلايا 

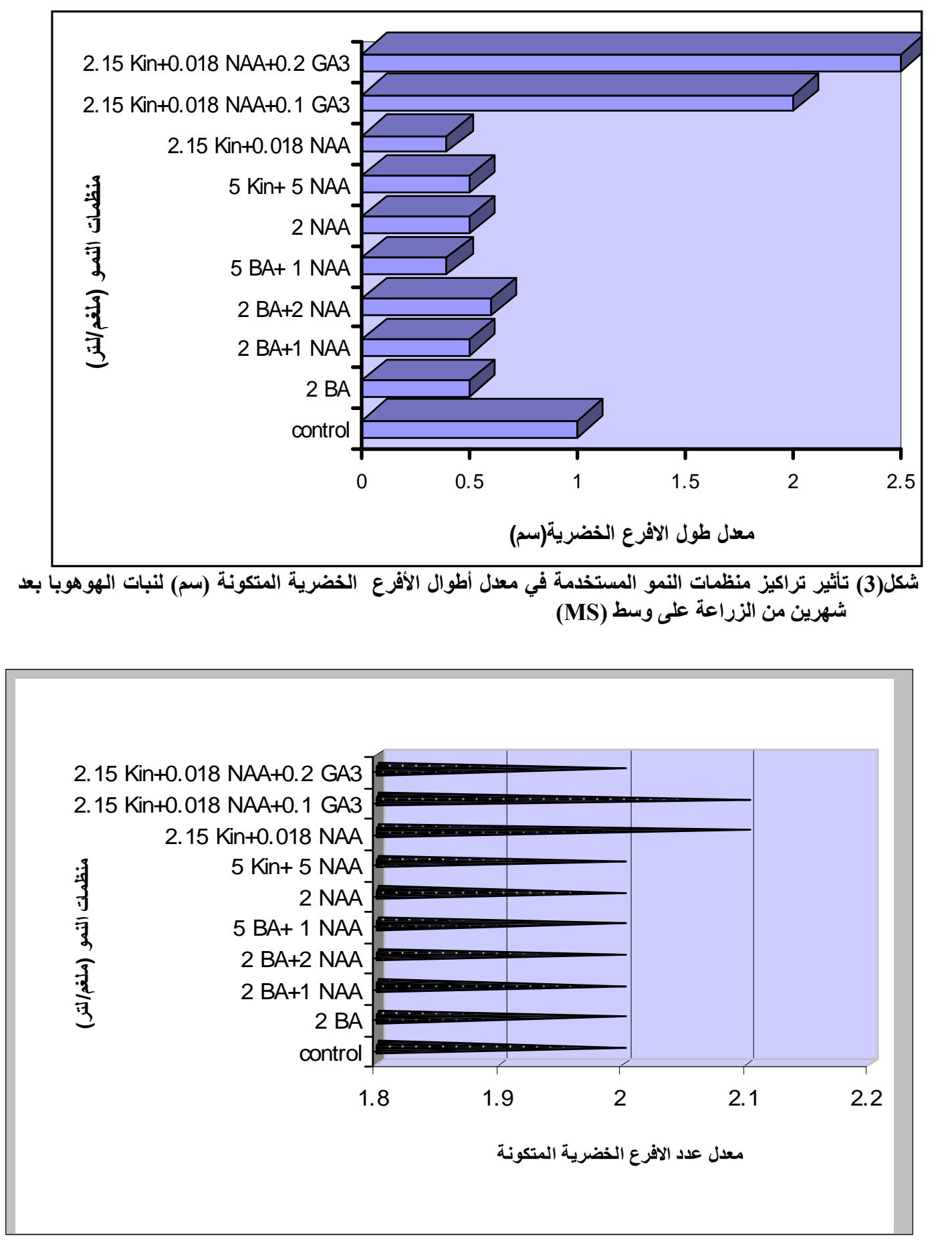

شكل(4) تأثير تراكيز منظمات النمو المستخدمة في معدل عدد الأفرع الخضرية المتكونة (التضـاعف) لنبات الهوهوبـا بعد شهرين من الزراعة على وسط (MS) 
by LC/MS/MS. Shokuhin Eiseigaku Zasshi, 46 (5): 198-204.

9- Naqvi, H.H. and Ting, I.P. (1990). Jojoba, A unique liquid wax producer from the American desert. pp. 247251. In: J. Janick and J.E. Simon (eds.), Advances in new crops. Timber Press, Portland, OR. D: Jojoba A Unique Liquid Wax Producer from the American Desert.htm

10-Verschuren, P. M. (1989). Evaluation of jojoba oil as a low- energy fat. 1. A 4-week feeding study in rats. Food and Chemical Toxicology, 27 (1):35-44

11-Habashy, R.R., Abdel-Naim, AB., Khalifa, A.E. and Al-Azizi, M.M. (2005). Anti-inflammatory effects of jojoba liquid wax in experimental models. Pharmacol. Res., 51 (2): 95105.

12-Boozer, C.N. and Herron, A.J.(2006). Simmondsin for weight loss in rats. Int. J. Obesity, 30 (7): 1143-1148.

13-Lein, S., Van Boven, M., Holser, R., Decuypere, E., Flo, G. and Lievens, S. (2002). Simultaneous determination of carbohydrates and simmondsins in jojoba seed meal (Simmondsia chinesis) by gaschromatography. J. of Cromatography (2) : 257-264

14-Perez-Gil, F., Sangines, G.L., Torreblanca, R.A., Grande, M.L. and Carranco, J.M. (1989). Chemical
1- Benzioni, A. (1997). Jojoba. New Crop

Fact

Sheet.

www.hort.purdue.edu/newcrop/cropfa ctsheets/jojoba.html

2- Stone, W.S. (1993). Simmondsiaceae (jojoba family). Jepson Flora Project, University of Calfornia.

3- Meyer, S.E.(2000) Simmondsia chinensis (Link) Schn., Simmondsiaceae-Jojoba family: 1-4. www.nsl.fs.fed.us/wpsm/Simmondsia. pdf

4- Shaker, S.T. (2005). Molecular differentiation of Jojoba. A thesis of M.Sc in Biotechnology. College of Science. Al-Nahrain University . Iraq.

5- Cantrel, C., Salomon, T.G., Brown, S.C., Marie, D. and Dubacq, J.P. (1991). Isolation and Biochemical Characteristics of Jojoba Simmondsia chinensis (Link) Schn. Plant and Cell Physiology, 32 (7): 959-967.

6- Low, C.B. ; Hackett, W.P. (1981). Vegetative propagation of jojoba. Calif. Agric., 35:3-4.

7- Evans, W.C. (1999). Trease and Evans ${ }^{\circ} \quad$ Pharmacognosy. $14^{\text {ed. }}$, Saunders Company Ltd.

8- Tada, A., Jin, Z.L., Sugimoto, N., Sato, k., Yamazaki, T. and Tanamoto, K. (2005). Analysis of the constituents in jojoba wax used as a food additive 
fragments. Acta Horticulturae 227(1): 411-413.

20-Liorente, B.E. and Apostolo, N.M. (1997). Effect of different growth regulators and genotype on in vitro Propagation of Jojoba. New Zealand Journal of Crop and Horticultural Science. (Abstract).

21-Agrawal, V., Prakash, S. and Gupta,S.C. (2004). Effective Protocol for in Vitro shoot Production Through Nodal Explants of Simmondsia chinensis. Biologia Plantarum, 45 (3):435-449

22-Jacoboni, A. and Standardi, A. (1987). Tissue culture of Jojoba (Simmondsia chinensis, Link). Acta Horticulturae (ISHS) 212(2): 557-560.

23- توفيق ، أروى عبد الكريم (2005) ـ دراسة

صفة تحمل الملوحة في خمسة أصناف من

الرز باستخدام تقنية زراعة الأنسجة النباتية.

أطروحة ماجستير ـ كلية العلوم - قسم علوم

الحياة (نبات)ـ الجامعة المستتصرية ـ العراق

24-Murashige, T. and Skoog, T. (1962).

A revised medium for rapid growth and bioassays with Tobacco tissue culture. Physiol. Plant., 15 : 473-497. 25- أبو زيد ، الثحات نصر (2000).

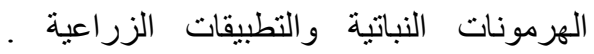

الطبعة الثانية ـ الدار العربية للنشر والتوزيع ، لهبه

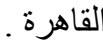

composition and content of antiphysiological factors of jojoba (Simmondsia chinesis) residual meal. Arch. Latinoam Nutr., 39 (4): 591600.

15-Medina Juarez, L.A. and Trejo Gonzalez, A. (1989). Elimination of toxic compounds, biological evaluation and partial characterization of the protein from jojoba meal ( Simmondsia chinensis [Link] Schn. ). Arch. Latinoam Nutr., 39 (4): 576590.

16- Dimmit, M.A. (2000). Simmondsiaceae (jojoba family). Arizona-Sonora Desert Museum.

17- Hamama, L., Baaziz, M. and Letouze, R. (2001). Somatic embryogenesis and plant regeneration from leaf tissue of jojoba. Plant Cell, Tissue and Organ Culture. 65: 109-113

18- Hamama, L., Baaziz, M. and Letouze, R. (2003). Regeneration of Jojoba by somatic embryogenesis, control of embryo formation, Polyamine content and role of the age of explants and growth Regulators. Acta Horticulturae 616: 313-320.

19-Scaramuzzi, F. and D'Ambrosio, A. (1988). Organogensis and propagation " in vitro " of Simmondsia chinensis (Link) Schn. (Jojoba) from vegetative 